\title{
"STRUCTURAL HEALTH MONITORING AND EARTHQUAKE EARLY WARNING: PRELIMINARY STUDIES FOR APPLICATION IN EASTERN SICILY,
}

\author{
Luciano Zuccarello ${ }^{1,2,3, *}$, Giuseppina Tusa ${ }^{1}$, Mario Paratore ${ }^{1}$, Carla Musumeci ${ }^{1}$, \\ Domenico Patanè 1
}

(1) Istituto Nazionale di Geofisica e Vulcanologia, Sezione di Catania Osservatorio Etneo, Catania, Italy

(2) Deparatmento de Fisica Teorica y del Cosmos, University of Granada, Granada, (Spain)

(3) Instituto Andaluz de Geofisica, University of Granada, Granada, Spain

Article history

Receveid February 27, 2017; accepted March 620, 2018.

Subject classification:

Eastern Sicily; Seismic Risk; Seismic Early Warning; Structural health monitoring.

\begin{abstract}
In this work, the reduction of seismic hazard in eastern Sicily is addressed by both studying the fundamental resonant frequency of strategic buildings through low cost geophysical investigation techniques, and exploring a practical approach to earthquake early warning EEW) system. The fundamental period and the corresponding amplification of some selected strategic buildings has been estimated using ambient vibration and earthquake data. We analyzed the basic dynamic parameters of buildings chosen as target, by using continuous vibration measurements at different floors. The dynamic behavior of structures was evaluated considering both small strains induced by ambient vibrations and larger excitation levels due to the earthquakes occurrence.

A practical approach to earthquake early warning in the investigated area was dealt with by using empirical relationships between parameters measured on the initial portion of seismic recordings and related to the earthquake magnitude and peak ground motion. In particular, we performed the first preliminary tests by using empirical relationships calibrated for the considered area and taking into account the geometry of the existing permanent seismic network deployed in the eastern Sicily. The estimated relationships have been used to provide onsite warning around a given seismic station and evaluate the potential damaging effects. The joint of EEW system and geophysical investigation shown in this work may be deemed a useful guide for the future implementation of the in real time seismic monitoring in the region.
\end{abstract}

\section{INTRODUCTION}

The research project POR-FESR "Attività di sviluppo sperimentale finalizzata alla riduzione del rischio sismico nella Sicilia orientale" has supported several research actions aimed to the earthquake hazard mitigation in Eastern Sicily. One of the main objectives of the project was to lay the foundations of the development of a low-cost structural health monitoring (SHM) system for buildings of strategic interest, combining the real-time strong motion monitoring system (RSMS) and the earthquake early warning system (EEWS).

As well known, SHM refers to the use of in-situ measurement (continuous or of routine) and analyses of key structural parameters, under operating conditions, for the purpose of warning in case of impending abnormal states in order to avoid not only casualties, but to give maintenance and rehabilitation advices, as well. The fundamental element of SHM is certainly a system of sensors that is required to monitor the structural status, for instance stress, displacement, acceleration, quality of foundation of a structure, and so on. The integration of SHM capabilities and EEW technologies for real-time damages assessment during an earthquake is a quite innovative application that has been receiving considerable attention since it gives the opportunity of possible real-time risk reduction actions. In particular, the EEWSs, which are now operational in several countries around the world (including Italy), use earthquake sci- 

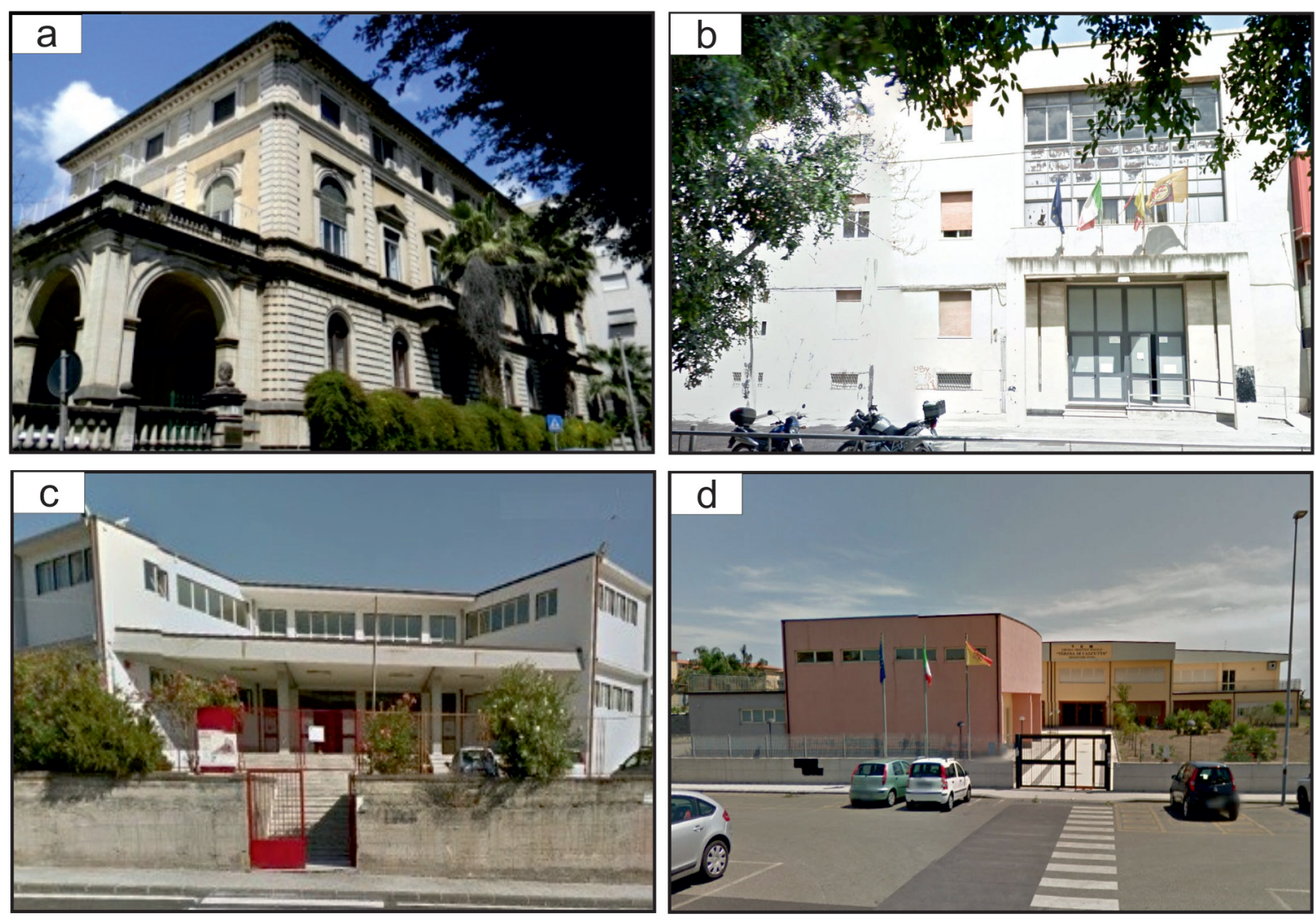

FIGURE 1. Pictures of the strategic buildings chosen for this study: (a) Osservatorio Etneo (Catania); (b) Dipartimento Protezione Civile (Messina); (c) Scuola Nazario Sauro (Catania); (d) Scuola M. T. Calcutta (Tremestieri Etneo).

ence and technology of monitoring systems to alert devices and/or people when shaking waves generated by an earthquake are expected to arrive at their location. In the line with the project requirements, in this paper we deal with the preliminary analyses for the future implementation of a monitoring system that provides for the integration of EEW tools with SHM ones in eastern Sicily. In particular, in the first part of the paper, we perform basic analysis of the structural dynamic characteristics of some strategic buildings chosen as targets. Therefore, we examine the first approach to development of an EEWS as a tool for real-time prediction of the ground motion and the potential damage caused by an earthquake through the rapid estimation of some EEW parameters related to destructiveness of an earthquake [e.g., Shieh et al., 2011; Lin et al., 2012].

As repeatedly demonstrated, the expected potential damage of a building is related to several factors, such as the structural typology, the resonant frequency. However, the geological condition of the site in which the building is located is largely important one, since the earthquakes can cause extensive damage in certain areas and relatively little in other ones. Consequently, assessing the amplification/attenuation due to surface geology is of primary importance for the definition of a specific seismic behavior for engineering design and land-use planning.

Site effects can be estimated by means of numerical simulations or experimental methods. Within the latter, fast and low-cost geophysical methods based on ambient vibration measurements have been recently developed in order to provide the predominant frequency of a site to be use for microzonation of first and second level (Level I and II, respectively). In this regard, the European research project Site EffectS assessment using AMbient Excitations (SESAME European project 2005) has been an important reference point. It has provided the practical user guidelines for the implementation of techniques for the characterization of local site effects, based on the combined use of ambient vibration recordings with the H/V spectral ratio method. The suggested method, also known as the "Nakamura technique" [Nakamura, 1989], was first introduced by Nogoshi and Igarashi [1971] starting from the previous work by Kanai and Tanaka [1961]. Even though it is not able to characterize the complexity of site effects alone, nor 
provide the absolute value of the amplification, this method can be used to estimate the fundamental period of soil deposits. This information is very important since represents the period at which the soil amplifies the ground motion caused by a seismic event. If it coincides or is equal to the fundamental period of manmade infrastructure, then there is a great possibility of strong damages [Mucciarelli et al., 2004; Navarro et al., 2004]. Following this technique, we deal with the topic of the health monitoring of structures potentially exposed to ground motion shaking from future earthquakes.

This issue will be monitored by analyzing the strongmotion records from temporary sensors installed in four different buildings located both in the cities of Catania and Messina. As suggested by the guidelines of the above-mentioned project with respect to the typology of structure to be selected (schools and strategic buildings for civil protection purposes), the chosen buildings are the following (Figure 1):

- Osservatorio Etneo (hereafter OE) (Istituto Nazionale di Geofisica e Vulcanologia), located in Piazza Roma n.2 Catania;

- Dipartimento della Protezione Civile in Messina (hereafter DPC), located in V.le S. Martino 336 Messina.

- Scuola Elementare N. Sauro (hereafter NS), located in Via T. Tasso 3 Catania;

- Scuola Elementare M. Teresa di Calcutta (hereafter MTC), located in Via Guglielmino 49, Tremestieri Etneo (CT).

Detailed description of the construction characteristics of the buildings is provided in Muratore [2018, this issue]. The valuable records provided by the installed sensors, both in terms of ambient seismic noise and seismic events, offer to us the opportunity to characterize the dynamic properties of the selected buildings through the estimation of their fundamental frequency.

After the occurrence of a seismic event, the fundamental frequency of a structure can change suggesting a potential damage undergone by the considered structure. Therefore, a real-time monitoring system of infrastructures, associated with a system able to give a rapid alert and a rapid assessment of long lasting damages in case of an impending seismic event, represents one of the most efficient solutions for the seismic risk mitigation in areas such as the urban ones, or the regions densely populated, or the zones with high industrial development. In particular, the real-time measurement of both ground and structural motion on one side, and the real-time prediction of ground motion and potential damage on the other, are certainly useful for the mitigation of the final beneficiaries' ex- posure to seismic risk. As will be discussed in the second part of this work, the prediction of ground motion and damaging potential of threatened earthquake are evaluated by considering two seismic early warning parameters that are the peak ground displacement $\left(P_{d}\right)$, and the predominant period $\left(\tau_{c}\right)$. We use them as indicators of a structurally damaging earthquake for the buildings under investigation. In fact, as shown by several authors, these two early warning parameters are empirically correlated to magnitude [e.g. $\mathrm{Wu}$ and Kanamori, 2005a, 2008; Kanamori, 2005; Zollo et al., 2006, 2010; Colombelli et al., 2012; Carranza et al., 2013] and to peak ground velocity and acceleration [e.g. Böse et al., 2007; Zollo et al., 2010; Carranza et al., 2013]. In particular, we test two early warning parameters by applying the method by Zollo et al. [2010] based on the real-time measurement of $P_{d}$ and $\tau_{\mathrm{c}}$ at recording sites located at increasing distances from the earthquake epicenter.

\section{STRUCTURAL DYNAMIC CHARACTERIZATION OF BUILDINGS}

In order to characterize the dynamic properties of the selected buildings, we have estimated their fundamental frequencies by using both earthquake and ambient noise data recorded by strong-motion and weak-motion temporary stations, respectively. The strong-motion stations have been installed at the highest accessible floor of each buildings; simultaneously, ambient noise measurements were performed outside the buildings, in free-field conditions, where velocimeters were deployed. During the data acquisition, the accelerometers have been placed as close as possible to the bearing structures to minimize vertical modes of beams or floors. In two buildings (OE and DPC) we also installed additional accelerometer sensors at the foundation level due to their greatest height. Since the seismic stations were installed both in free-field conditions and inside the buildings, we have chosen to orient toward the north all the sensors.

The fundamental period of buildings has been analyzed by using the Horizontal (H) to Vertical (V) Spectral Ratio (HVSR) technique. In particular, the computation of the $\mathrm{H} / \mathrm{V}$ ratio follows different steps:

- data correction for the instrumental transfer function;

- selection of the most stationary time windows (e.g., using an anti-triggering algorithm) in order to avoid transient noise;

- computation and smoothing of the Fourier ampli- 
tude spectra for each time windows (a Hanning taper and Konno-Ohmachi smoothing type was applied);

- average the two horizontal component (using a quadratic mean);

- computation of the H/V ratio for each window;

- computation of the average $\mathrm{H} / \mathrm{V}$ ratio.

This methodology, originally adopted as a quick estimate of the seismic site response [Nakamura, 1989], is a very useful tool to estimate the dynamic properties of buildings, as demonstrated in several cases [e.g., Oliveira and Navarro, 2009; Gallipoli et al., 2009, 2010]. In buildings in which the seismic stations were installed both at the basement floor and at the top floor, the fundamental period was also obtained by computing the ratio between the amplitudes of the Fourier spectrum of horizontal components of motion, recorded at two different floors [Parolai et al., 2005]. This method, known as Standard Spectral Ratio (SSR) technique, characterizes the dynamics of the structure, removing the ground foundation movements. In the following, we describe the results obtained for each of the four selected sites.

\subsection{OSSERVATORIO ETNEO (CT)}

Osservatorio Etneo (OE) (Figure 1a) is the first building we have chosen for our analysis. It belongs to the Istituto Nazionale di Geofisica e Vulcanologia (INGV) and is located in the historical centre of Catania. The $\mathrm{OE}$ consists of a masonry structure, about $14 \mathrm{~m}$ high, and made up of four stories of varying height. The structure is very complex and characterized by middle floors (second and third) not uniformly distributed. Moreover, during its life, the building has been modified with significant structural changes, such as the addi- tion of a top floor and the inclusion of some concrete elements . Due to this complexity, the dynamic response has been evaluated through different methods of analysis and by using different types of seismic source.

Two mobile 24-bit seismic stations (Nanometrics Taurus; http://www.nanometrics.ca), equipped with three components accelerometer (Kinemetrics Episensor FBA ES-T; http://www.kinemetrics.com), have been deployed inside the building. The installations have been carried out on two levels, locating the sensors on the same vertical axis. In particular, the first station, called CTOES, has been placed at the building basement, while the second one, called CTOET, has been installed on the top floor.

In order to analyze the vibration modes of the building, it has been necessary to remove the contribution due to the ground motion in the frequency domain. For this reason, a third seismic station, called CTOEV, equipped with a $3 \mathrm{C}$ broadband sensor Lennartz LE-3D 20s (http://www.lennartz-electronic.de) has been installed in a plinth detached from the structure reproducing a free-field condition. By using the seismic signals recorded by the three seismic stations, we have been able to:

(i) compare the seismic signals of the stations located in the basement (CTOES and CTOEV), in order to study the spectral contribution of the sub-soil;

(ii) compare the signals of the two accelerometric stations (CTOES and CTOET), in order to analyze the seismic signal amplification along the structure, and the directional fundamental period.

Any significant spectral peaks of the H/V function have been highlighted at the station CTOEV. This result, in agreement with the one obtained by station CTOES, suggests that no fundamental resonance frequencies,

\begin{tabular}{|c|c|c|c|c|c|c|c|c|c|c|c|c|}
\hline Event name & $\begin{array}{c}\text { Data } \\
\text { (yyyy-mm-dd) }\end{array}$ & $\begin{array}{l}\text { Lat. } \\
\left({ }^{\circ}\right)\end{array}$ & $\begin{array}{l}\text { Long. } \\
\left(^{\circ}\right)\end{array}$ & $\begin{array}{l}\text { Depth } \\
(\mathrm{km})\end{array}$ & $\mathrm{M}_{\mathrm{L}}$ & $\begin{array}{l}\text { Epicentral } \\
\text { distance } \\
(\mathrm{km})\end{array}$ & Station & $\begin{array}{l}\text { PGA } \\
\text { (gal) }\end{array}$ & $\begin{array}{l}\text { PGV } \\
(\mathrm{cm} / \mathrm{s})\end{array}$ & $\tau_{c}(s)$ & $P_{d}(\mathrm{~cm})$ & $\begin{array}{l}\text { Alert } \\
\text { level }\end{array}$ \\
\hline \multirow[b]{2}{*}{ Greece } & \multirow[b]{2}{*}{$2014 / 02 / 03$} & \multirow[b]{2}{*}{38.290} & \multirow[b]{2}{*}{20.310} & \multirow[b]{2}{*}{10} & \multirow[b]{2}{*}{6.1} & \multirow[b]{2}{*}{460} & CTOES & 0.0076 & 0.0007 & 1.0 & $1.5 \mathrm{E}-07$ & 1 \\
\hline & & & & & & & СTOET & 0.0159 & 0.0014 & 1.2 & $3.2 \mathrm{E}-05$ & 1 \\
\hline \multirow{2}{*}{ Floresta } & \multirow{2}{*}{$2014 / 03 / 08$} & \multirow{2}{*}{37.962} & \multirow{2}{*}{14.890} & \multirow{2}{*}{8} & \multirow{2}{*}{4.1} & \multirow{2}{*}{52} & CTOES & 0.0035 & 0.0003 & - & - & - \\
\hline & & & & & & & CTOET & 0.0106 & 0.0007 & 0.7 & $6.9 \mathrm{E}-06$ & 0 \\
\hline \multirow[t]{2}{*}{ Tripi } & \multirow[t]{2}{*}{$2014 / 06 / 07$} & \multirow[t]{2}{*}{38.046} & \multirow[t]{2}{*}{15.097} & \multirow[t]{2}{*}{9} & \multirow[t]{2}{*}{3.7} & \multirow[t]{2}{*}{58} & CTOES & 0.0010 & 0.0001 & - & - & - \\
\hline & & & & & & & СТОЕТ & 0.0076 & 0.0007 & 0.5 & $1.5 \mathrm{E}-07$ & 0 \\
\hline
\end{tabular}

TABLE 1. Source and ground motion parameters for the three recorded events by the CTOES and CTOET strong-motion stations. 


\section{Seismic event $08 / 03 / 2014(\mathrm{M}=4,1)$}

(a)

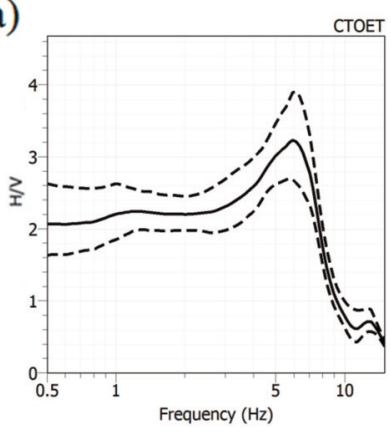

(b)

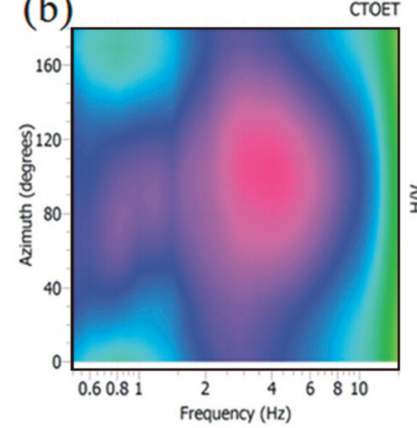

(c)

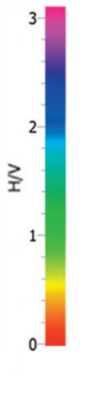

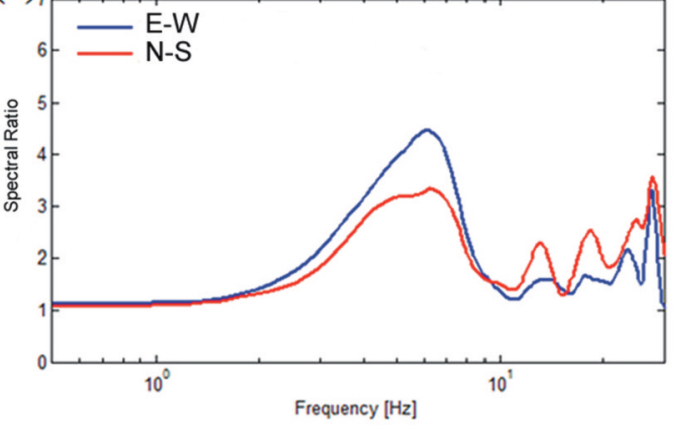

FIGURE 2. Spectral analysis of S-phase and surface waves of the seismic event (Floresta earthquake) recorded at CTOET station. (a) $\mathrm{H} / \mathrm{V}$ average spectral ratios (continuous line) and $\pm 1 \mathrm{dev}$. stand. (dotted lines), (b) contour map of directionality, (c) $\mathrm{H}_{\mathrm{n}-\mathrm{s}} / \mathrm{H}_{\mathrm{n}-\mathrm{s}}$ and $\mathrm{H}_{\mathrm{e}-\mathrm{w}} / \mathrm{H}_{\mathrm{e}-\mathrm{w}}$ spectral ratio (red curve $\mathrm{N}-\mathrm{S}$ component, blue curve $\mathrm{E}-\mathrm{W}$ component).

\section{Seismic event $03 / 02 / 2014(M=6,1)$}

(a)

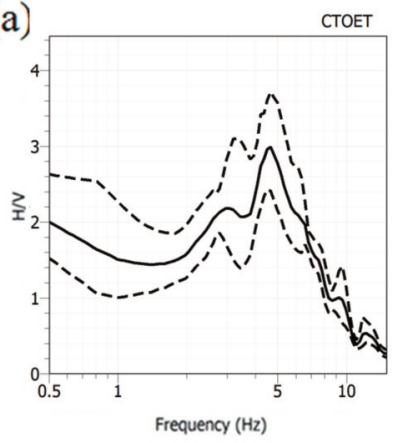

(b)

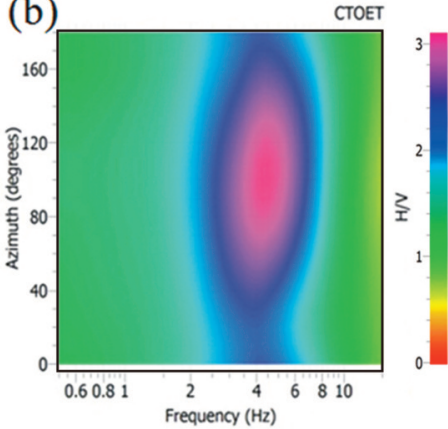

(c)

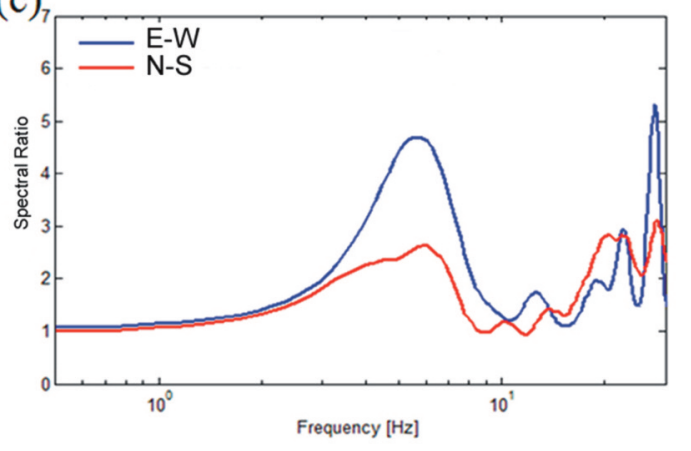

FIGURE 3. Spectral analysis of S-phase and surface waves of the seismic event (Greece earthquake) recorded at CTOET station. (a) $\mathrm{H} / \mathrm{V}$ average spectral ratios (continuous line) and $\pm 1 \mathrm{dev}$. stand. (dotted lines), (b) contour map of directionality, (c) $\mathrm{H}_{\mathrm{n}-\mathrm{s}} / \mathrm{H}_{\mathrm{n}-\mathrm{s}}$ and $\mathrm{H}_{\mathrm{e}-\mathrm{w}} / \mathrm{H}_{\mathrm{e}-\mathrm{w}}$ spectral ratio (red curve $\mathrm{N}-\mathrm{S}$ component, blue curve $\mathrm{E}-\mathrm{W}$ component).

both for the free-field and for the building foundation floor, have been found, as we expected by the geological features of the underlying Osservatorio Etneo soil [Capilleri et al., 2016].

As previously stated, we have performed a similar analysis taking into account the seismic recordings acquired by the same stations during the occurrence of three earthquakes (see Table 1). The selected earthquakes satisfy the following criteria:

(i) minimum distance source-to-building;

(ii) maximum magnitude;

(iii) best Signal-to-Noise-Ratio (SNR).

For each event, we have carried out the HVSR analysis by using both S- and surface waves. Even in this case, no significant peaks associated to the resonance frequencies at the level of the building foundation floor (CTOES station) have been achieved. On the contrary, we have found $\mathrm{H} / \mathrm{V}$ spectral peaks on the top of build- ing (CTOET station), spanning the frequency band 4-6 $\mathrm{Hz}$ (Figures $2 \mathrm{a}$ and $3 \mathrm{a}$ ). Figures $2 \mathrm{~b}$ and $3 \mathrm{~b}$ show the directionality diagrams, obtained by the rotation of the $\mathrm{H} / \mathrm{V}$ function from $0^{\circ}$ to $180^{\circ}$. The results show seismic signal amplification along the east-west component.

The spectral ratio between horizontal components (Standard Spectral Ratio method, SSR) recorded during the seismic events by the stations located at the highest floor and the basement one confirms the previous results. In particular, SSR analysis has been carried out for the Floresta earthquake ( $M=4.1)$, and Greece earthquake ( $M=6.1$ ) (for more details, see Table 1). In both cases, we have obtained a well highlighted spectral peak at 6 $\mathrm{Hz}$, referable to the first mode of vibration of the $\mathrm{OE}$ building (Figure 2c and 3c). As shown in the $\mathrm{H} / \mathrm{V}$ directional diagrams, we again observe amplification effects on the east-west component. To corroborate our results, we have applied the SSR method to the seismic 


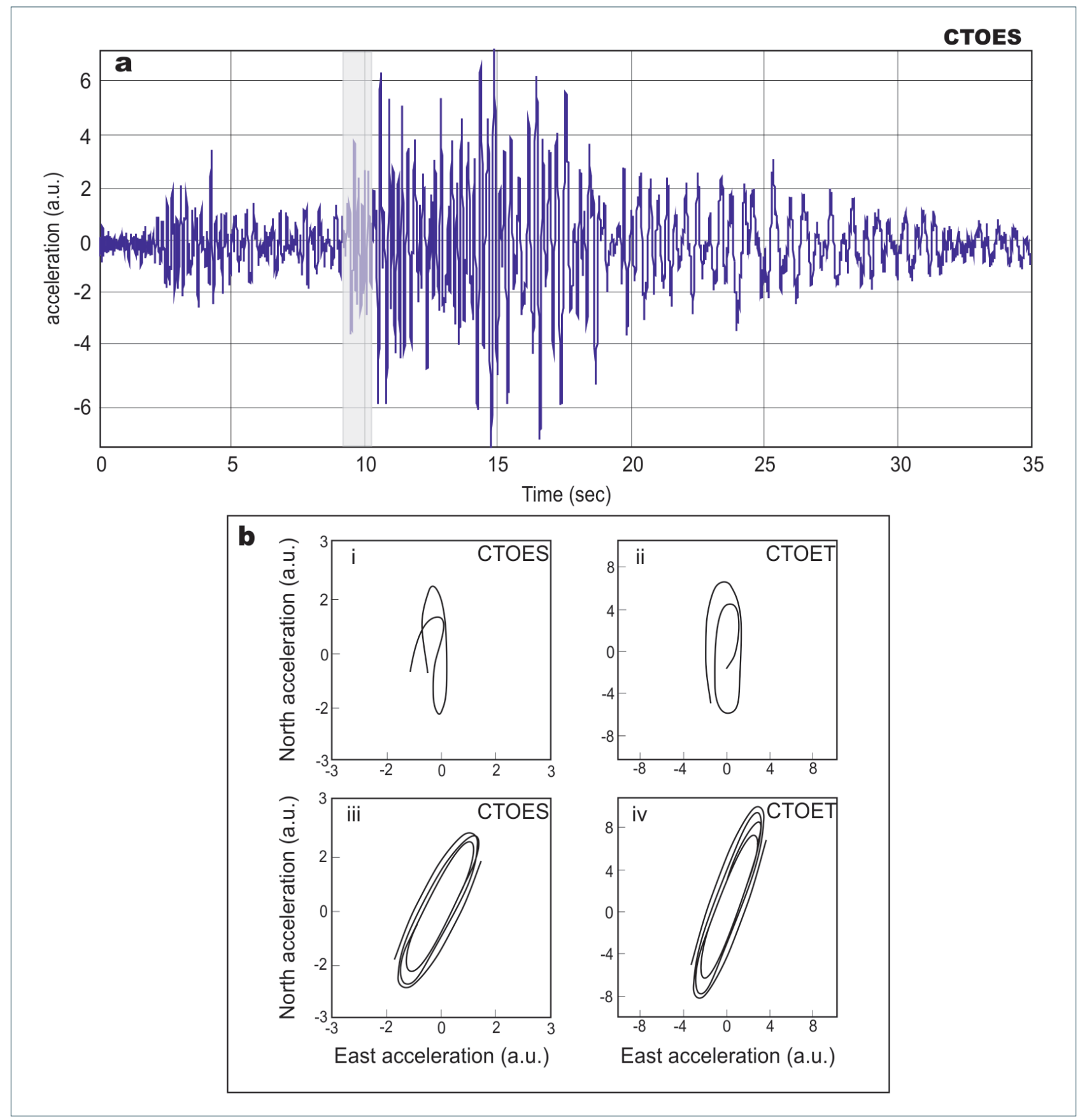

FIGURE 4. (a) Floresta earthquake (E-W component) recorded at CTOES. (b) Particle motion on 3-5 Hz (i, ii) and 5-7 Hz (iii, iv) frequency band calculated on the first S-waves (highlighted in grey).

noise data, as well, coming to the same results and suggesting that the OE building shows the same dynamic characteristics in the elastic domain, regardless the source and undamaged conditions.

Due to the strategic importance of this building, we have achieved particle motion analysis on $2.56 \mathrm{~s} \mathrm{long} \mathrm{time} \mathrm{win-}$ dow starting from the S-wave picking of the Floresta earthquake $(M=4.1)$. We repeated this analysis on $2.56 \mathrm{~s}$ long time window relative to the maximum amplitude waveform in the seismic signal. This kind of study permits to know the building shear response during earthquakes, and allows to check the seismic motion amplitude and direction at the different floors (Figure 4). We have detected an amplification of the particle motion recorded at the terrace level than that associated to the basement one (amplification of about 2 and 4 in the frequency bands $3-5 \mathrm{~Hz}$ and $5-7 \mathrm{~Hz}$, respectively). Finally, no rotations on the direction of oscillation at the different floors have been detected.

\subsection{DPC BUILDING IN MESSINA}

The DPC building (Figure 1b) consists of three floors and a basement. Essentially, it is a masonry building, 


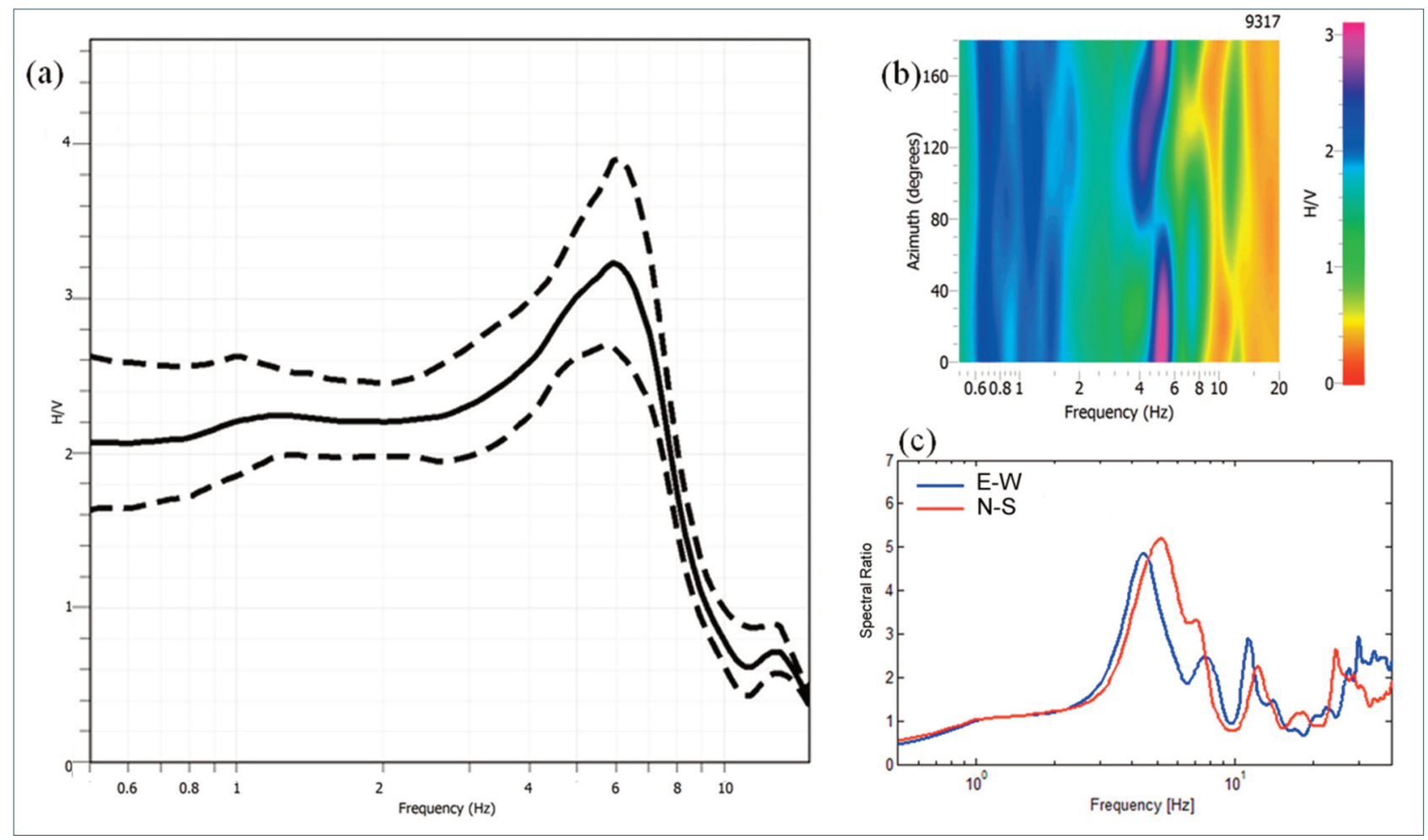

FIGURE 5. (a) H/V average spectral ratios (continuous line) and \pm 1 dev. stand. (dotted lines), (b) Contour map of directionality, (c) $\mathrm{H}_{\mathrm{n}-\mathrm{s}} / \mathrm{H}_{\mathrm{n}-\mathrm{s}}$ and $\mathrm{H}_{\mathrm{e}-\mathrm{w}} / \mathrm{H}_{\mathrm{e}-\mathrm{w}}$ spectral ratio (red curve $\mathrm{N}-\mathrm{S}$ component, blue curve $\mathrm{E}-\mathrm{W}$ component) of ambient seismic noise recorded on the second floor of the DPC building.

but with the addition of different reinforced concrete elements. In particular, it is possible to distinguish two sections:

(i) the north section, divided into only two floors and characterized by masonry pillars and reinforced concrete beams;

(ii) the south section, characterized by load-bearing walls and, some weakly reinforced concrete walls in the basement floor.

Two 24 bit mobile seismic stations [Reftek 130; http://www.reftek.com] with three components accelerometers [Kinemetrics Episensor FBA ES-T; http://www.kinemetrics.com] have been installed at the basement and at the second floor. Similarly, also in this test site we have analyzed the seismic noise through the HVSR method. No evidence of significant peaks of the $\mathrm{H} / \mathrm{V}$ function has been found at the station installed at the basement floor. On the contrary, a clear resonance peak at a frequency of $5 \mathrm{~Hz}$ has been found at the station installed on the second floor of the building (Figure 5a). The directionality diagrams, through a rotation of the $\mathrm{H} / \mathrm{V}$ function from $0^{\circ}$ to $180^{\circ}$, reveal an isotropic seismic response of the structure. (Figure 5b). Finally, the results obtained through the HVSR analyses have been confirmed by the SSR technique, too. Also in this case we found a peak at $4.5 \mathrm{~Hz}$ in the EW component, and another one at $5 \mathrm{~Hz}$ in the NS component. These values can be attributed to the first vibrational mode of the building (Figure $5 \mathrm{c}$ ).

\subsection{NS AND MTC ELEMENTARY (CT)}

The buildings holding the elementary schools are concrete structures built in two different periods. The NS school (Figure 1c) has been realized in $70^{\text {th }}$, before the seismic classification of the area, and is characterized by a basement floor with retaining concrete walls and isolated foundation plinths built on different ground assessment [Muratore, 2018, this issue]. The MTC school (Figure 1d) is a new building consisting of two floors designed with seismic code provisions, and located near to a seismic active fault on Tremestieri Etneo area [Paratore et al., 2018, this issue].

In both the schools, a mobile 24 bit seismic station [Reftek 130; http://www.reftek.com] equipped with three components accelerometers [Kinemetrics Episensor FBA ES-T; http://www.kinemetrics.com] at the highest floors (first floor in the Madre Teresa di Calcutta School and terrace in N. Sauro School) have been installed. Moreover, a mobile seismic station equipped with short period $4.5 \mathrm{~Hz}$ geophone has been installed in the free field. Even at these buildings, the structural monitoring was performed by using the spectral ratios with single-station technique (HVSR method). 

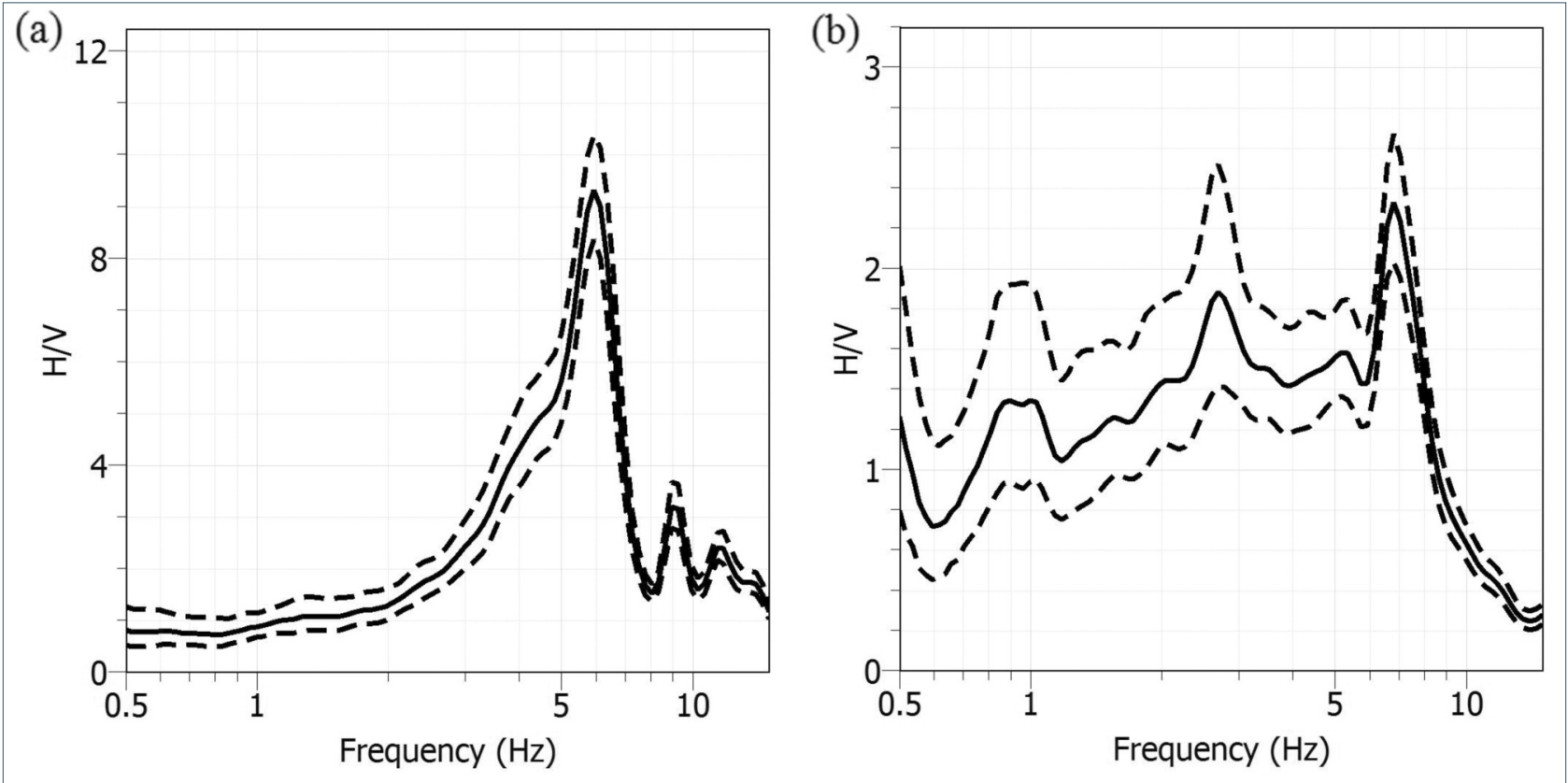

FIGURE 6. (H/V spectral ratio (continuous line) and $\pm 1 \mathrm{dev}$. stand. (dotted lines) of ambient seismic noise, recorded on the top floor of the NS School (a) and MTC School (b).

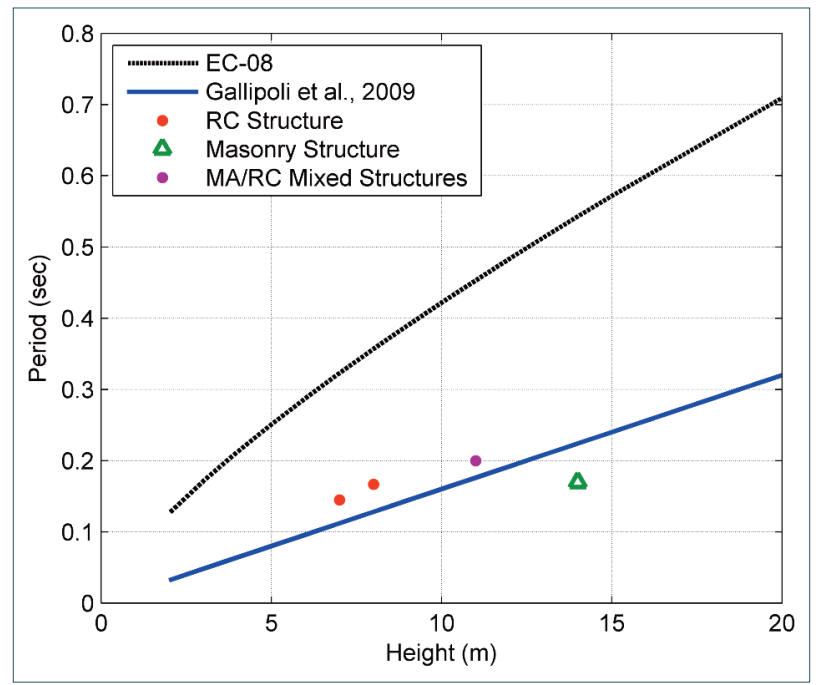

FIGURE 7. Comparison of the period-height relationships of this study with relationships obtained by other authors. Green triangle stands for Osservatorio Etneo building, the red dots represent the two schools and the violet dot depicts the Dipartimento Protezione Civile edifice.

As shown in Figure 6a, H/V peak at the NS school has been detected at the frequency of $6 \mathrm{~Hz}$. This value can be assigned to resonance frequency of the building. Instead, Figure $6 \mathrm{~b}$ shows the spectral ratios of the seismic noise signal recorded at the MTC school. In this case, the resonant peak was observed at the frequency of $7 \mathrm{~Hz}$. The MTC building is located in a particular geodynamic context, since the test site is crossed by a sec- tion of the Tremestieri Fault. During this research project, detailed studies on Tremestieri Etneo site were conducted in order to analyze the amplification and polarization effects in the fault zone [Paratore et al., 2018, this issue].

\subsection{CORRELATIONS BETWEEN EXPERIMENTAL ANAL- YSIS AND THEORETICAL MODELS}

The obtained experimental data, in terms of fundamental period of the selected buildings, have been compared with two well-known period (T)-height $(\mathrm{H})$ relationships taking into account the different construction typologies of the buildings under investigation (masonry structures and concrete buildings with or without earthquake resistant design). The fundamental period on the two orthogonal components, calculated only through micro tremor measurements, has been taken into account. Figure 7 shows the obtained couples of values period-height for the test sites, together with the empirical laws given in the EC8 $\left(T=0.075 H^{0.75}\right.$, CEN [2004]), and the one by Gallipoli et al. [2009]. This last corresponds to the fundamental periods of 244 reinforced concrete buildings, distributed in four European countries. Similarly to our analysis, the authors performed seismic ambient noise measurements inside buildings with height in the range 2-5 floors. As shown in the Figure 7, the values belonging to the RC buildings are aligned above the regression curve representing the empirical law by Gallipoli et al. [2009], while the masonry building shows a slightly lower value. In contrast, 
the equation provided by the EC8 [CEN, 2004] shows an over-estimation of building periods. A similar mismatch was observed between several curves obtained by experimental measurements [e.g., Navarro et al., 2007; Gallipoli et al., 2009; Masi and Vona, 2009], and the the EC8 theoretical law. Panzera et al. [2016] suggest that this disagreement may be due to the use of a low energy input source such as the one by the ambient noise. However, different types of seismic source have been taken into account in this study, always obtaining the same values of the fundamental period. This evidence highlights the importance of combining experimental measurements to numerical simulations.

\section{EARTHQUAKE EARLY WARNING SYSTEM [EEWS]}

\subsection{FIRST APPROACH TO EEW FOR EASTERN SICILY}

Thanks to the advance in seismology and telemetry technologies, earthquake early warning systems are thus becoming more promising to reduce the potential effects of seismic risk and minimize the impact of the large earthquakes in a given area. In fact, during the past two decades, EEWSs have been implemented around the world, and some of them are in development or being tested, for instance, in southern Italy [AMRA; http://www.amracenter.com/it/]. Such is the background to this study, in which we have dealt with the first approach for future practical applications of an EEWS in eastern Sicily in the context of actions to mitigate seismic risk.

The earthquake warning time needed to alert the population depends on the configuration of the seismic network associated to the EEWS, as well. In general, two different approaches to EEWS can be distinguished:

(i) the so-called "regional" warning system, which is characterized by a wide seismic network with a good azimuthal coverage of the seismic source area;

(ii) the "on-site" or "site-specific" warning system, which is based on single seismic sensor or a seismic array deployed in proximity of a target site to alert.

The first approach to EEWS yields stable but late estimates of seismic source parameters and therewith warnings and the seismic alert may be issued before the ground motion hits in a large portion of the region (blind zone). Instead, the second one allows for faster earthquake information but, at the same time, less reliable [Kanamori, 2005]. However, the on-site approach is able to enhance the safety margin of target site since several automated security measures can be activated in order to reduce the exposition of it. In both cases, however, the development of the EEWS is become the focus of considerable research effort and its potential applicability for the immediate activation of safety measures for critical systems is already undoubted [e.g., Wieland et al., 2000; Kanda et al., 2008; Sato et al., 2011].

Recently, Tusa et al. [2017] have estimated empirical scaling relationships between the peak ground displacement $\left(P_{d}\right)$ and the characteristic period $\left(\tau_{c}\right)$, and magnitude, and between peak ground velocity $(P G V)$ and $P_{d}$, by using the broadband velocity seismograms of more than 200 seismic events occurring in eastern Sicily. The dataset chosen in this work, included earthquakes recorded by the stations of the permanent seismic network belonging to the Istituto Nazionale di Geofisica e Vulcanologia (INGV) Sezione di Catania-Osservatorio Etneo (Figure 8). The actual geometry of the seismic network ensures a good focal azimuthal coverage, and makes this case study a good test for the application of EEWS methodologies. Indeed, the network is dense enough to fulfill the requirements of azimuthal coverage better than $180^{\circ}$ for the $75 \%$

\begin{tabular}{|c|c|c|c|c|c|c|c|c|c|c|}
\hline \multicolumn{11}{|c|}{ Equation 1} \\
\hline & a & SEa & b & $\mathrm{SE}_{\mathrm{b}}$ & c & $\mathrm{SE}_{\mathrm{c}}$ & d & $\mathrm{SE}_{\mathrm{d}}$ & RMSE & $\mathrm{R}^{2}$ \\
\hline $2 \mathrm{P}$ & -5.915 & 0.053 & 0.981 & 0.010 & -1.876 & 0.031 & - & - & 0.2912 & 0.7087 \\
\hline $4 \mathrm{P}$ & -5.944 & 0.109 & 1.010 & 0.012 & -1.852 & 0.065 & - & - & 0.2823 & 0.7334 \\
\hline $2 \mathrm{~S}$ & -5.518 & 0.052 & 1.072 & 0.011 & -1.982 & 0.029 & - & - & 0.3152 & 0.7314 \\
\hline \multicolumn{11}{|c|}{ Equation 2} \\
\hline & $a^{\prime}$ & Cl95 for a' & $b^{\prime}$ & Cl95 for b' & & & & & WSE* & $\mathrm{R} 2$ \\
\hline $2 \mathrm{P}$ & -8.812 & 0.216 & 1.022 & 0.057 & & & & & 0.0777 & 0.9818 \\
\hline $4 \mathrm{P}$ & -8.757 & 0.205 & 1.035 & 0.054 & & & & & 0.0771 & 0.9840 \\
\hline $2 S$ & -8.488 & 0.228 & 1.090 & 0.060 & & & & & 0.0868 & 0.9823 \\
\hline
\end{tabular}

TABLE 2. Coefficients of equations 1 and 2 for the prediction of $\log _{10}\left(P_{d}\right)$ and $\log _{10}\left(P_{d}\right) 30 \mathrm{~km}$, respectively (by Tusa et al., 2017). SE indicates standard error of coefficient estimates; CI95 indicates the confidence intervals at 95\% confidence level; RMSE indicates the root mean squared errors; $\mathrm{R}^{2}$ is the coefficient of determination. 
of the seismic events (the average value of the gap on about 11000 seismic events recorded between 2008 and 2017 is $150^{\circ}$ ) and ability to localize even low energy events, down to $\mathrm{M}_{\mathrm{L}} \sim 0.7$.

Following the approach by Zollo et al. [2006, 2007], Tusa et al. [2017] measured the $P_{d}$ by using $2 \mathrm{~s}$ and $4 \mathrm{~s}$ $\mathrm{P}$-waves time windows (denoted as $2 P$ and $4 P$, respectively) and $2 \mathrm{~s}$ for the $\mathrm{S}$-wave (denoted as $2 \mathrm{~S}$ ), starting from the P- and S-waves picked arrivals. As it will be shown later, these parameters are the input data needed to rapidly detect an earthquake by the software used to make offline tests on real data. The parameter $P_{d}$ is related to magnitude $(M)$ and hypocentral distance $(R)$ through the standard attenuation relation [Campbell, 1985; Wu and Zhao, 2006; Zollo et al., 2006; Lancieri and Zollo, 2008]:

$$
\log _{10}\left(P_{d}\right)=a+b M+c \log _{10}(R)
$$

where the coefficients $a, b$, and $c$ have been estimated by a robust linear regression to the data through an iteratively reweighted least-squares (IRLS) algorithm with a bisquare weighting function (see Table 2). Therefore, the equation (1) has been used to correct the observed peak amplitudes for the distance effects, by normalizing them to a reference distance of $30 \mathrm{~km}$. Finally, a linear regression line was computed for the means of $\log 10\left(P_{d}\right)^{30 k m}$ weighted by the inverse of standard deviation $(\sigma)$ as [Zollo et al., 2006]:

$$
\log _{10}\left(P_{d}\right)^{30 k m}=a^{\prime}+b^{\prime} M
$$

Table 2 lists the estimated coefficients $\mathrm{a}^{\prime}$ and $\mathrm{b}^{\prime}$ together with the calculated weighted standard errors (WSE) [see Tusa et al., 2017 for major details]. The authors found an evident positive correlation between the logarithmic peak displacement normalized to $30 \mathrm{~km}$ $\left[\log _{10}\left(P_{d} d^{30 \mathrm{~km}}\right)\right]$ and the local magnitude for $2 \mathrm{P}, 4 \mathrm{P}$, and $2 \mathrm{~S}$ time windows in the whole investigated magnitude range.

The characteristic period, $\tau_{c}$, is defined as $[\mathrm{Wu}$ and Kanamori, 2005a]:

$$
\tau_{c}=2 \pi \sqrt{\frac{\int_{0}^{\tau_{0}} u^{2}(t) d t}{\int_{0}^{\tau_{0}} v^{2}(t) d t}}
$$

where $u(t)$ and $v(t)$ are the ground-motion displacement and velocity, respectively. The integration is taken over a time window starting at the $\mathrm{P}$ wave onset time with a duration equal to $\tau_{0}$, generally set to $3 \mathrm{~s}$. $\tau_{c}$ can be considered to represent the average period of Pwave signal and several studies have shown that it re- flects the magnitude of earthquakes [Kanamori, 2005; $\mathrm{Wu}$ and Kanamori, 2005b]. For the estimation of $\tau_{c}$, Tusa et al. [2017] considered the ground motion filtered (high-pass filtered at $0.075 \mathrm{~Hz}$ ) displacement, $u(t)$, and velocity, $v(t)$, from the vertical component record, while the parameter $\tau_{0}$ has been set to $3 \mathrm{~s}$. Considering hypocentral distance less than $60 \mathrm{~km}$ (for larger hypocentral distances the decay rate is less severe because of no-direct energy arrivals) [for more details, see Tusa et al., 2007] they estimated the following equation:

$$
\log _{10}\left(\tau_{c}\right)=0.143( \pm 0.070) M_{L}-0.853( \pm 0.266)
$$

where $\tau_{c}$ is measured in seconds, suggesting that the average $\log _{10}\left(\tau_{c}\right)$ values increase with increasing magnitude. The uncertainties associated to the two coefficients of the model are the 95\% confidence intervals.

Wu and Kanamori [2005a] showed that $P_{d}$ is correlated with the $P G V$ at the same site, and when $P_{d}>0.5$ $\mathrm{cm}$, the event is most likely able to produce damages. Tusa et al. [2017] estimated the equation that relates $P G V$ to $P_{d}$ through linear regression, obtaining the following best-fit regression line:

$$
\log _{10}(P G V)=1.36( \pm 0.05)+0.91( \pm 0.02) \log _{10}\left(P_{d}\right)
$$

where the units of $P G V$ are $\mathrm{cm} / \mathrm{s}$ and of $P_{d}$ are $\mathrm{cm}$. Note that the $P G V$ values are measured as the maximum amplitude between the two unfiltered horizontal components of ground motion velocity. The standard deviation of $\log _{10}(P G V)$ is 0.27 , whilst the coefficient of determination is 0.80 . Therefore, in real-time, the measured $P_{d}$ and $\tau_{c}$ are used to calculate the level of shaking (that is $P G V$ ) at the target sites, and $M$, respectively, even though $M$ is not directly used for onsite early warning purposes. All the empirical laws described above, represent the important inputs for the estimation of both source and ground motion parameters by the software platform we have used to perform the preliminary tests in the eastern Sicily.

\subsection{OFFLINE TEST WITH REAL DATA}

In order to implement an EEWS, we performed data analysis by using the code PRESTo (Probabilistic and Evolutionary early warning SysTem) by Satriano et al. [2011]. It is mainly based on the RTLoc [Satriano et al., 2008] and RTMag [Lancieri and Zollo, 2008] algorithms for real-time earthquake location and magnitude estimation, respectively. In particular, the computed parameters are continuously refined with time, and the 


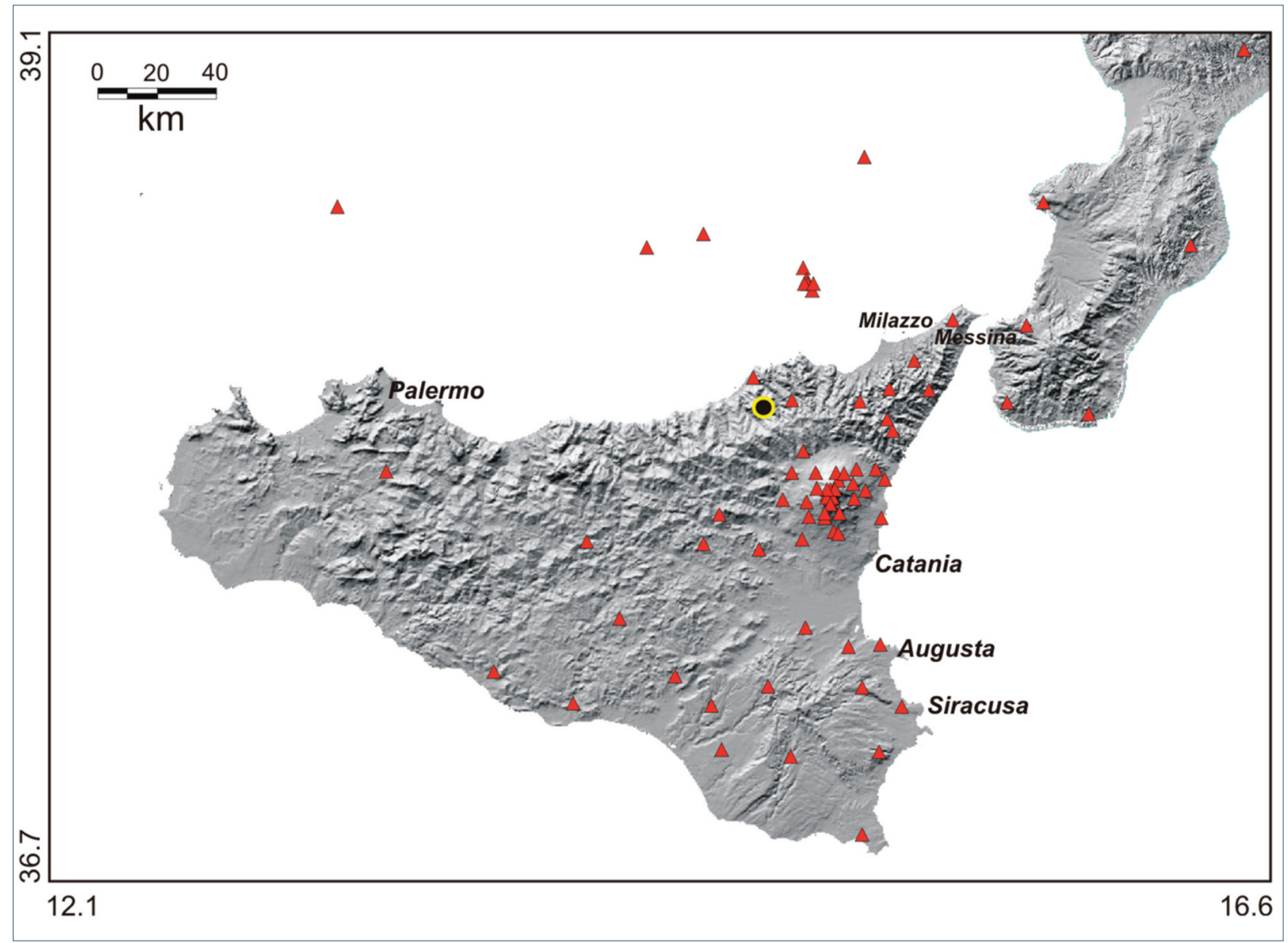

FIGURE 8. Geographic distribution of the permanent stations of the "Rete Sismica Permanente della Sicilia Orientale" (RSPSO) (red triangles). The black circle indicates the epicentral localization of the event used to perform the test with the code PRESTo (see text for details).

computation is based on a probabilistic earthquake location and a Bayesian approach to magnitude evaluation. It is worth noting that the module RTMag implemented inside PRESTo makes use of empirical correlation laws between $\log \left(P_{d}\right)$ and magnitude, such as equation 1 , normalizing to a reference hypocentral distance of $10 \mathrm{~km}$. However, the use of a different normalization distance only changes the intercept of the regression line in equation 2, whilst the slope, and thus the interpretation, remain unchanged. Before starting the simulation, the system has been configured by including

(i) the characteristics of seismic network (station coordinates and sensor type),

(ii) the control parameters for the several steps of data analysis, and

(iii) the 1D velocity model for P- and S-waves derived from Hirn et al. [1991].

Playing back the recorded traces into PRESTo, we can evaluate the accuracy of the earthquake parameter predictions and the speed of convergence for both location and magnitude estimates. The delays between the variation of estimated parameters and their processing through PRESTo, depend on the parceling of data into 1-s packets and the computation time of the code. The performance of empirical laws by Tusa et al. [2017] has been tested considering some of the strongest events recently recorded in the area. Here, we show the results we obtained with the code PRESTo in terms of source and ground-motion parameters for a $\mathrm{M}_{\mathrm{L}} 4.6$ (23 June 2011) earthquake. It occurred close to Tortorici village (see star in Figure 8), at about $45 \mathrm{~km}$ away from an important refinery close to Milazzo village (ME). In the Figure 9, we show the temporal evolution of the earthquake parameters estimated by PRESTo on the base of the empirical scaling relationships previously discussed. In particular, looking at the Figure 9, we can quantitatively analyze the results of the computation and see how quickly the system can produce stable and reliable estimates of the earthquake parameters on the basis of 

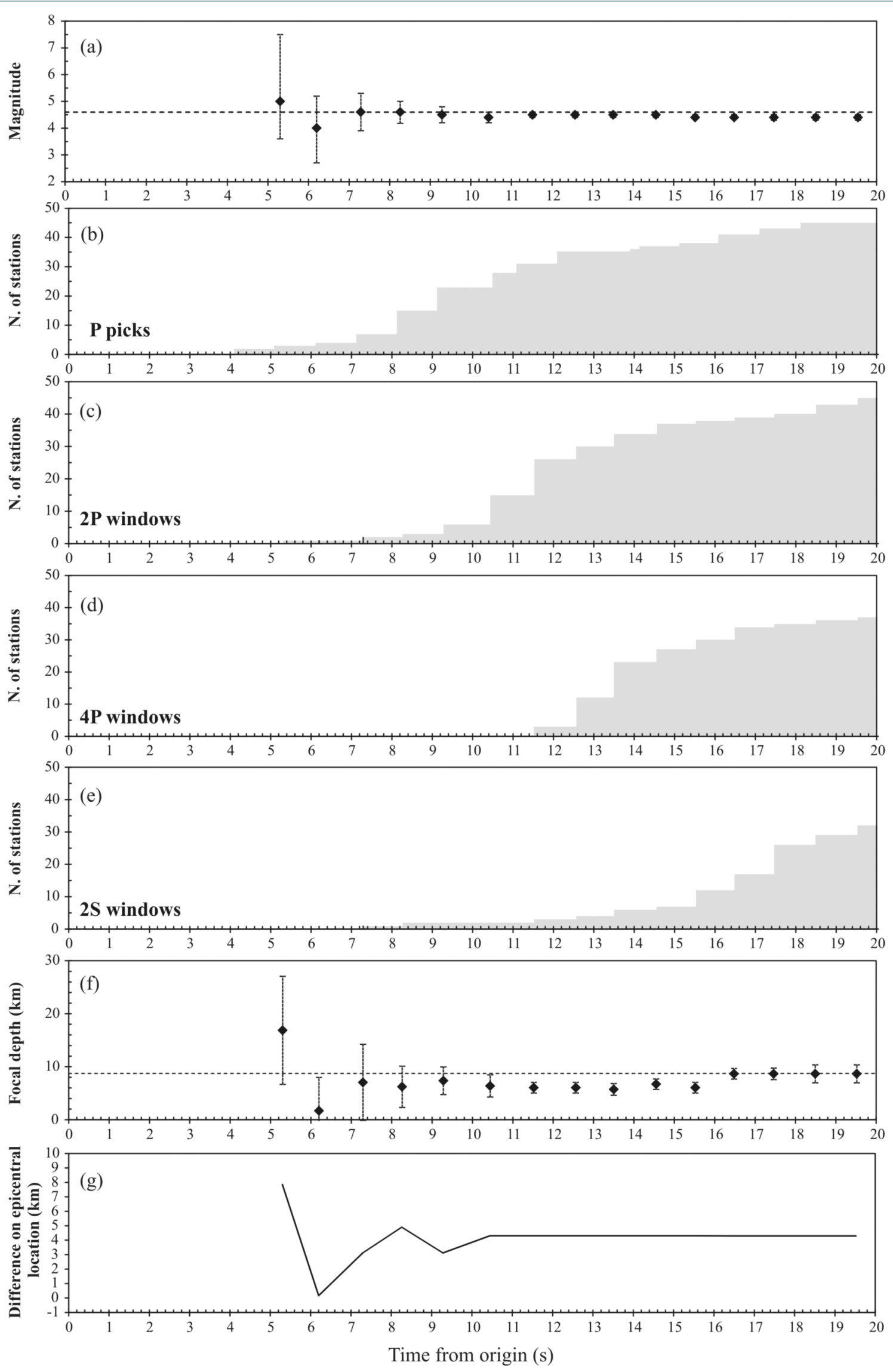

FIGURE 9. PRESTo timeline for the $\mathrm{M}_{\mathrm{L}}$ 4.6, 23 June 2011 earthquake occurring near the village of Tortorici. The dashed line in the plots (a) and (f) represent the reference magnitude and focal depth, respectively, obtained from the catalog. 
the information coming from the actual seismic network. The first input parameters are the P-phase picks that are required by the phase association algorithm and the location module. In particular, before declaring an event at least 3 picks within $5 \mathrm{~s}$ must be acquired by the system. This condition is reached $5.09 \mathrm{~s}$ after the event origin time (Figure 9b), when three stations trigger. The first location is available $0.2 \mathrm{~s}$ later with a difference with respect to the reference epicentral location and focal depth (namely the ones from the seismic catalog) of about $8 \mathrm{~km}$.

At the same time, the first magnitude estimate is 5.0 with an associated uncertainty (Figure 9a), defined as the confidence interval between 5\% and 95\% (M equal to 3.6 and to 7.5 , respectively). This estimation is associated to the $2 \mathrm{P}$ window available at the nearest station (in our case at about $8 \mathrm{~km}$ from the epicenter; Figure 9c). At $6.2 \mathrm{~s}$ from the origin, another $2 \mathrm{P}$ window is available (estimate by the second station close to the epicenter) and the estimated magnitude reaches 4.0 with smaller error (spanning the 2.7-5.2 magnitude range).

As more $P_{d}$ measurements are acquired by the system, the magnitude estimation through the empirical regression model is more and more refined and the uncertainty decreases. In fact, at about 8s (15 $\mathrm{P}$ picks) from the origin time the magnitude settles at $4.6 \pm 0.4$, which is reasonable for an early warning application. Our results show that with the actual network configuration, both location and magnitude estimations are fairly stable and reliable after about 8s from the origin time, when the system gives expected lead times (i.e. the time interval between the arrival of $\mathrm{S}$ waves and alert notification equal to $7 \mathrm{~s}$ at Milazzo, $13 \mathrm{~s}$ at Catania and $14 \mathrm{~s}$ at Messina). This means that when the event is declared the expected lead times are about 3 s longer. However, the effective lead-time depends on the level of accuracy and robustness of the warning required by the recipients. In fact, if the location and the magnitude need to be stable for a given number of stations before warning is communicated, then the effective lead time would be smaller.

PRESTo integrates the regional approach to early warning with the on-site, threshold-based method by Zollo et al. [2010] for the independent definition of local alert levels at each station. This approach has the advantage that the potential damaging effects of the earthquake are evaluated without requiring accurate real-time location of the event. This is particularly useful when the distribution of the stations is very sparse and does not guarantee an optimal azimuthal coverage to obtain an early and reliable location of the epi- center. In the threshold approach, the peak displacement $P_{d}$ and the dominant period $\tau_{\mathrm{c}}$ in a short time window after the first P-arrival time (here $3 \mathrm{~s}$ ) are computed at each station and compared with a priori selected threshold values, that define a decisional table with four alert levels [from 0 to 3, see Zollo et al., 2010 for details]. These levels are connected to both the expected on-site damages and the damages at distance. Considering a threshold value of macroseismic intensity IMCS (Mercalli-Cancani-Sieberg Intensity Scale) for damage effects equal to VII, we can estimate the PGV expected by using the regression relationships by Faenza and Michelini [2010]. Note that the MCS Intensity scale is used in Italy to describe the earthquake ground shaking and its effects on communities and the built environment. For IMCS=VII the Faenza and Michelini [2010] empirical law predicts $P G V=6 \mathrm{~cm} / \mathrm{s}$, that we can convert into $P_{d}$ threshold value by using the equation (5) and taking 1 standard deviation, obtaining $P_{d}=0.1 \mathrm{~cm}$. The $\tau_{\mathrm{c}}$ threshold can be estimated through the equation (4) for a minimum magnitude value fixed as threshold. On the basis of seismic history of the region, we selected $M_{L} 5$, estimating a $\tau_{c}=0.7 \mathrm{~s}$. Figure 10 shows the time evolution of $P_{d}$ and $\tau_{c}$ measurements for the $M_{L} 4.6$ seismic event we considered above, and the alert levels which have been associated to the recording sites. The first measurements of $P_{d}$ and $\tau_{c}$ are available after $6.1 \mathrm{~s}$ from the origin time, or after $3.1 \mathrm{~s}$ from the first P-pick at the nearest station to the epicenter. According to $P_{d}$ and $\tau_{\mathrm{c}}$ values, the system associates to this station an alert level 3 [damage expected nearby and far from stations, Zollo et al., 2010] since both measurements are higher than the threshold values. The values of $\tau_{c}$ remain stable with time (or with distance; see Figure 10a) and consistent from one station to another. Conversely, $P_{d}$ shows a decreasing trend with time or distance (Figure 10b), as expected, and the values rapidly drop under the threshold value (alert level 1; see Figure 10c). In this case study, only at nearest station to epicenter the threshold values are reached and surpassed. On the contrary, if there are a certain number of near source stations where $P_{d}$ and $\tau_{\mathrm{c}}$ exceed the threshold values, the real-time mapping of alert levels can be used to predict the Potential Damage Zone (PDZ) [Zollo et al., 2010], namely the area in which the highest intensity levels are expected. This is particularly important to guarantee an efficient planning of rescue operations during emergency phases immediately after an earthquake.

The predictable capacity of the threshold values for both $\tau_{\mathrm{c}}$ and $P_{d}$ have been additionally tested considering the seismic events recorded by the strong motion 


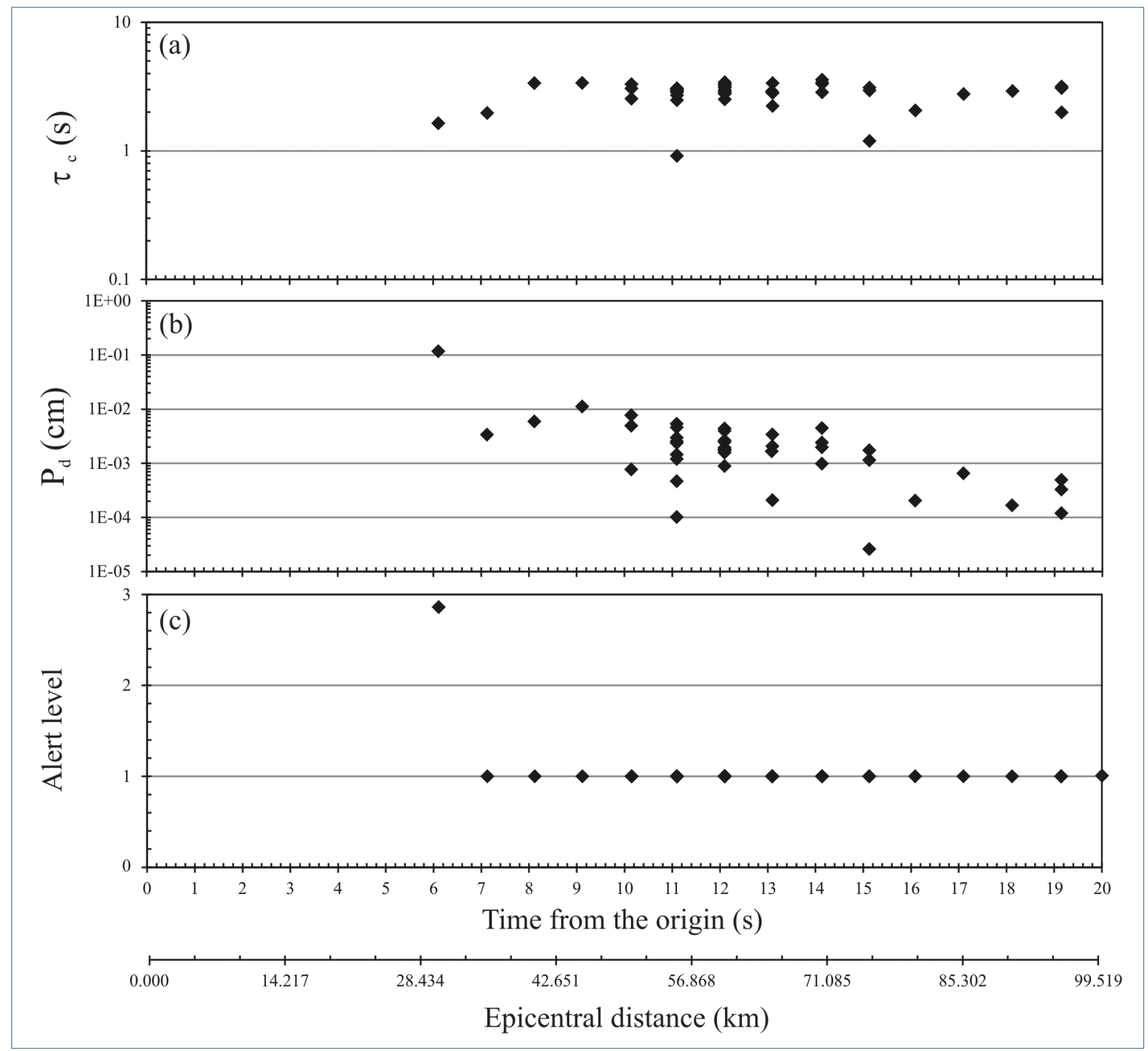

FIGURE 10. Evolution in time of the ground parameters (a) $\tau_{\mathrm{c}}$, (b) $P_{d}$, and (c) the corresponding alert level at the different stations for the $M_{L}$ 4.6, 23 June 2011 earthquake as estimated by the code PRESTo.

sensors installed in the Osservatorio Etneo's building (CTOES and CTOET) during their working period. In this time span, the two stations had recorded 3 earthquakes (see Table 1), including the $2014 \mathrm{M}_{\mathrm{L}}=6.1$ Greece (epicentral distance $=460 \mathrm{~km}$ ) earthquake, as well. As expected, none of these seismic events had caused damage to the building. However, the records from these earthquakes provided by the above mentioned sensors offer an opportunity for us to examine the use of $\tau_{c}$ and $P_{d}$ measurements at a single site for the onsite EEW purpose. Table 1 lists source and ground motion parameters (PGA, PGV) together with the EEW parameters $\left(\tau_{\mathrm{c}}\right.$ and $P_{d}$ ), for the three considered seismic events at stations CTOES and CTOET, considering only the records providing a good enough signal-to-noise ratio (higher than
2) for the analysis. In fact, as indicated by several studies [e.g., Wu et al., 2007; Shieh et al., 2011], the parameters $\tau_{\mathrm{c}}$ is particularly sensitive to signal-to-noise ratio. Looking at the Table 1 , we can firstly realize that the peak foundation accelerations (station CTOES) are lower than those estimated on the top of building (station CTOET), suggesting that the seismic response of the building in the terrace level is more energetic than in the basement. Secondly, $\tau_{\mathrm{c}}$ appears to be correlated with the size of the events, while $P_{d}$ shows values lower than the threshold of $0.1 \mathrm{~cm}$ as expected for both small earthquakes (such as the Floresta and Tripi seismic events) and large earthquakes recorded at local and regional/teleseismic distances (such as the Greek earthquake), respectively. 


\section{CONCLUDING REMARKS AND FUTURE PROSPECTS}

The combination of a real-time strong motion monitoring (RSMS), performed for structural health monitoring (SHM) of strategic structures, with an earthquake early warning system (EEWS) is today becoming one of the most effective strategies to mitigate seismic risk in short time-scales. Thanks to the technological evolution together with the advances in seismological knowledge, the joint RSMS and EEWS analysis represent a moderately costly solution through earthquake disaster mitigation. In this work, we dealt with the first approaches for the future realization of such systems in eastern Sicily, starting from the preliminary study of the structural dynamic behavior of some buildings that we selected as potential target sites.

For this purpose, both small and larger excitation levels due to ambient noise and earthquakes shaking, respectively, were considered and no difference in the fundamental frequency estimations have been found. Additionally, by analyzing the performances of the different techniques used on the two types of construction (reinforced concrete and masonry), we obtain similar results regardless of which method applied. In particular, SSR appears to be the most reliable method for assessing frequency, returning specific values with a reasonable difference on orthogonal components. Moreover, several authors [e.g., Gallipoli et al. 2009] observed that in some instances, the fundamental periods obtained using the HVSR technique are higher than those obtained through the SSR method. Such cases could be due to the choice of the reference site location. In our case, the reference site was located inside the building. However, this configuration does not seem significantly affect the average fundamental frequency estimations.

First test for the development of the EEWS has been performed by using the high-quality data collected by the seismic network deployed in the eastern Sicily area. We have demonstrated that this seismic network is dense enough to allow the PRESTo platform to converge to a stable determination of the location and magnitude estimation within 2-3 s from the event declaration. At the same time, thanks to the on-site threshold-based EEWSs [Zollo et al., 2010] faster earthquake information can be obtained for the target site, such as a building of strategic interest. Indeed, the EEWS approach performed in this work can provides rapid estimation of structural response (damaging or no damaging earthquake) of important lifelines and strategic structures, suitably instrumented. It associates an alert level to each site defined on the base of the peak ground displacement and fundamental period of first waves. Furthermore, the real-time monitoring of structure at different floors could give us other important seismic parameters that can be used to estimate the building response and structural damage, such as for example the story drift angle, that can be calculated by the observed displacement and floor height and associating to it threshold values similarly to peak ground displacement.

In conclusion, the combined implementation of the systems mentioned above could represent an optimal solution for the seismic risk mitigation in high seismic risk areas. Thanks to the real-time monitoring of infrastructures we could reach two important targets:

i) the rapid prediction of the ground motion and potential damage of an impending earthquake, supporting the emergency response quickly during the initial response;

ii) the monitoring of resonance frequencies of a structure at different floors for the assessment of permanent damages, since shift of the resonance frequency is indicative of damage undergone by the monitored structure.

Acknowledgements. This work has been supported by the following project: "Attività di sviluppo sperimentale finalizzata alla riduzione del rischio sismico nella Sicilia Orientale" inside the PO-FESR 2007-2013 Sicilia; MED-SUV funded from the European Union Seventh Framework Programme (FP7) under Grant agreement $n^{\circ} 308665$. This work is sponsored by European Union's Horizon 2020 research and innovation programme under the Marie Sklodowska-Curie grant agreement $n^{\circ} 798480$. We are thankful to Salvatore Rapisarda and Danilo Contrafatto to support us in the field work.

\section{REFERENCES}

Azzaro, R., S. D’Amico, A. Mostaccio, L. Scarfi and T. Tuvè (2006). Terremoti con effetti macrosismici in Sicilia orientale nel periodo gennaio 2002-dicembre 2005. Quad. Geofis. 41, INGV, Roma (in Italian).

Böse, M., C. lonescu and F. Wenzel (2007). Earthquake early warning for Bucharest, Romania: novel and revised scaling relations, Geophys. Res. Lett., 34, L07302, doi: 10.1029/2007GL029396.

Campbell, K.W. (1985). Strong motion attenuation relations: a ten-year perspective, Earthquake Spectra, 1, 759-804.

Capilleri, P.P., E. Motta, E. Raciti and M. Todaro (2016). Seismic response of a strategic building in Catania 
(ltaly) by 2-D FEM analysis, Procedia Engineering, 158, 523-528, doi: 10.1016/j.proeng.2016.08.483.

Carranza, M., E. Bufon, S. Colombelli and A. Zollo (2013). Earthquake early warning for southern lberia: a $\mathrm{P}$ wave threshold-based approach, Geophys. Res. Lett., 40, 4588-4593.

CEN (2004). Eurocode 8: Design of structures for earthquake resistance, Part 1: General rules, seismic actions and rules for buildings, European Committee for Standardization, EN 1998-1:2004, Brussels, 2004.

Colombelli, S., A. Zollo, G. Festa and H. Kanamori (2012). Early magnitude and potential damage zone estimates for the great Mw 9 Tohoku-Oki earthquake, Geophys. Res. Lett., 39, L22306, doi: 10.1029/2012GL053923.

Faenza, L. and A. Michelini (2010). Regression analysis of MCS intensity and ground motion parameters in Italy and its application in ShakeMap, Geophys. J. lnt., 180, 1138-1152.

Gallipoli, M.R., M. Mucciarelli and M. Vona (2009). Empirical estimate of fundamental frequencies and damping for Italian buildings, Earthquake Engineering Structural Dynamics, 38, 973-988.

Gallipoli, M.R., M. Mucciarelli, B. Šket-Motnikar, P. Zupanćić, A. Gosar, S. Prevolnik, M. Herak, J. Stipčević, D. Herak, Z. Milutinović and T. Olumćeva (2010). Empirical estimates of dynamic parameters on a large set of European buildings, Bull. Earth. Eng., 8, 593-607.

Hirn, A., A. Nercessian, M. Sapin, F. Ferrucci and G. Wittlinger (1991). Seismic heterogeneity of Mt. Etna: structure and activity, Geophys. J. Int., 105, 139153.

Kanda, K., T. Nasu, M. Miyamura and E. Koide (2008). Development of site-specific earthquake early warning system for hazard mitigation, 14th WCEE, Beijing, China, Oct 12-17

Kanamori, H. (2005). Real time seismology and earthquake damage mitigation, Ann. Rev. Earth. Planet. Sci., 33, 195-214.

Lancieri, M. and A. Zollo (2008). A bayesian approach to the real-time estimation of magnitude from the early P and S wave displacement peaks, J. Geophys. Res., 113, B12302, doi: 10.1029/2007JB005386.

Lin, C.C.J., P.Y. Lin, T.M. Chang, T.K. Lin, Y.T. Weng, K.C. Chang and K.C. Tsai (2012). Development of on-site earthquake early warning system for Taiwan. Earthquake Research and Analysis - New Frontiers in Seismology. S. D’Amico Ed. ISBN: 978-953-307840-3, InTech.

Masi, A. and M. Vona (2009). Experimental and numeri- cal evaluation of the fundamental period of undamaged and damaged RC buildings, Bull. Earth. Eng., 8, 643-656, doi:10.1007/s10518-009-9136-3. Mucciarelli, M., M.R. Gallipoli, A. Masi, M. Vona, F. Ponzo and M. Dolce (2004). Analysis of RC building dynamic response and soil-building resonance based on data recorded during a damaging earthquake (Molise, Italy 2002), Bull. Seism. Soc. Am., 94, 5, 1943-1953.

Muratore, M. (2018). Seismic vulnerability of strategic and relevant buildings : the study cases of the two edifices of the DRPC in Messina and INGV in Catania and of the two shools "C.D. Nazario Sauro" in Catania and "C.D. Teresa di Calcutta" in Tremestieri Etneo (CT), Ann. of Geophys. (submitted for publication on this volume).

Nakamura, Y. (1989). A method for dynamic characteristics estimation of subsurface using microtremors on the ground surface, Quarterly Rept. RTRI, Japan, 30.

Navarro, M. F. Vidal, M. Feriche, T. Enomoto, F. J. Sánchez and 1. Matsuda (2004). Expected ground-RC building structures resonance phenomena in Granada city (southern Spain), Proceedings of the 13th World Conference on Earthquake Engineering, Vancouver, BC, Canada, 1-6 August 2004, Paper No. 3308.

Navarro, M. F. Vidal, T. Enomoto, F.J. Alcalá, A. GarcíaJerez, F.J. Sánchez and N. Abeki (2007). Analysis of the weightiness of site effects on reinforced concrete (RC) building seismic behaviour: The Adra town example (SE Spain), Earth. Eng. Struct. Dyn., 36, 1363-1383.

Nogoshi, M. and T. Igarashi (1971). On the amplitude characteristics of microtremor (part 2), J. Seism. Soc. Japan, 24, pp. 26-40.

Oliveira, C.S. and M. Navarro (2009). Fundamental periods of vibration of RC buildings in Portugal from in-situ experimental and numerical techniques, Bull. Earth. Eng., 8(3), 609-642.

Panzera, P., S. D’Amico, G. Lombardo and E. Longo (2016). Evaluation of building fundamental periods and effects of local geology on ground motion parameters in the Siracusa area, 1taly, J. Seismol., 20, 1001-1019, doi:10.1007/s10950-016-9577-5.

Paratore, M., L. Zuccarello, G. Tusa, D. Contrafatto and D. Patanè (2018). Seismic amplification effects in near-fault zone: the case study of the Tremestieri fault close the T. di Calcutta school (Catania), Ann. Geophys. (submitted for publication on this volume).

Parolai, S., A. Facke, S.M. Richwalski and L. Stempniewski (2005). Assessing the vibrational frequencies of the Holweide Hospital in the city of Cologne (Germany) 
by means of ambient seismic noise analysis and FE modeling, Nat. Hazards, 34, 217-230.

Patanè, D. and M. Mattia (2017). A review of seismic hazard in the Eastern Sicily, Ann. of Geophys. (submitted for publication on this volume).

Sato, S., K. Ashiya, S. Yamamoto, N. Iwata, M. Korenaga and S. Noda (2011). Practical use of the Earthquake Early Warning (EEW) system for Shinkansen, Proceedings of the 9th World Congress on Railway Research, Lille, France.

Satriano, C., A. Lomax, and A. Zollo (2008). Real-time evolutionary earthquake location for seismic early warning, Bull. Seism. Soc. Am., 98, 1482-1494, doi: $10.1785 / 01200601590$.

Satriano, C., L. Elia, C. Martino, M. Lancieri and A. Zollo (2011). PRESTo, the earthquake early warning system for southern ltaly: concepts, capabilities and future perspectives, Soil Dyn. Earth. Eng., 21, 137-153.

Site Effects Assessment using Ambient Excitations (SESAME) European project, (2005). Deliverable D23.12, Guidelines for the implementation of the $\mathrm{H} / \mathrm{V}$ spectral ratio technique on ambient vibrations: measurements, processing and interpretation, http://sesame-fp5.obs.uif-grenoble.fr/SES_Technical Doc. Htm.Shieh, J.T., Y.M. Wu, L. Zhao, W.A. Chao and C.F. Wu (2011). An examination of TC $\mathrm{Pd}$ earthquake early warning method using a strong-motion building array, Soil Dyn. Earth. Eng., 31, 240-246.

Tusa, G., C. Musumeci, and D. Patané (2017). Estimation of earthquake early warning parameters for eastern Sicily, Bull. Seism. Soc. Am. (In press).

Wieland, M., M. Gresser and C. Kuendig (2000). Seismic early warning system for a nuclear power plant, Proceedings of the 12th World Conference on Earthquake Engineering, Auckland, New Zeland.

Wu, Y.M., and H. Kanamori (2005a). Rapid assessment of damage potential of earthquakes in Taiwan from the beginning of $\mathrm{P}$ waves, Bull. Seism. Soc. Am., 95, 1181-1185.

Wu, Y.M., and H. Kanamori (2005b). Experiment on an onsite early warning method for the Taiwan early warning system, Bull. Seism. Soc. Am., 95, 347-353.

$\mathrm{Wu}$, Y.M., H. Kanamori, R.M. Allen, and E. Hauksson (2007). Determination of earthquake early warning parameters, $\tau p$ and Pd for southern California, Geophys. J. Int., 170, 711-717.

$\mathrm{Wu}$, Y.M., and L. Zhao (2006). Magnitude estimation using the first three seconds P-wave amplitude in earthquake early warning, Geophys. Res. Lett., 33, L16312, doi: 10.1029/2006GL0268714.

Zollo, A., M. Lancieri and S. Nielsen (2006). Earthquake magnitude estimation from peak amplitudes of very early seismic signals on strong motion records, Geophys. Res. Lett., 33, L23312, doi:10.1029/2006GL027795.

Zollo, A., M. Lancieri and S. Nielsen (2007). Reply to comment by P. Rydelek et al. on "Earthquake magnitude estimation from peak amplitudes of very early seismic signals on strong motion records”, Geophys. Res. Lett., 34, L20303, doi:10.1029/2007GL030560.

Zollo, A., O. Amoroso, M. Lancieri, Y.M. Wu and H. Kanamori (2010). A threshold-based earthquake early warning using dense accelerometer networks, Geophys. J. Int., 183, 963-947.
*CORRESPONDING AUTHOR: LUCiano ZUCCARELLO,

Istituto Nazionale di Geofisica e Vulcanologia, Sezione di Catania - Oseervatorio Etneo, Catania, Italy email: luciano.zuccarello@ingv.it

(c) 2018 the Istituto Nazionale di Geofisica e Vulcanologia. All rights reserved. 